\title{
$>$ Metafísica e racionalidade tecnocientífica em Marcuse
}

> Metaphysics and technoscientific rationality in Marcuse

\section{por Antônio José Nascimento}

Doutor em Filosofia pela UÉvora, Mestre em Economia pela Unicamp e professor do Departamento de Economia da UFS. E-mail: ajntoinho@outlook.com. ORCID: 0000-0002-69700617.

\section{Resumo}

Marcuse é um dos pensadores contemporâneos que mais empenho dedicou à tarefa de extrair consequências práticas de seu diagnóstico das sociedades tecnificadas, no sentido de que procurou construir as mediações sociais necessárias para se promover a superação da dominação racional da ordem tecnológica do mundo em que vivemos. Nesse tocante, o presente ensaio assinala seu protagonismo no entendimento do caráter produtivista da tecnociência moderna $\mathrm{e}$ de seu funcionamento injuntivo. Mais do que um processo marcado pela dimensão irracional da metafísica, conforme indicação do próprio Marcuse, ver-se-á aqui, num breve contraponto com a abordagem heideggeriana da consumação da metafísica na técnica, como a objetivação processadora da Zivilisation moderna se inscreve já no âmago da maquinação produtivista da metafísica ocidental.

Palavras-chave: Filosofia. Tecnologia. Tecnociência. Racionalidade. Metafísica. Marcuse. Heidegger.

\begin{abstract}
Marcuse is one of the contemporary thinkers who has devoted the most effort to extracting practical consequences from his diagnosis of technified societies, as he sought to construct the social mediations necessary to promote the overcoming of the rational domination of the technological order of the world. In this regard, this essay highlights his protagonism in understanding the productivist character of modern technoscience and its injunctive functioning. More than a process marked by the irrational dimension of metaphysics, it will be seen here, in a brief counterpoint with the Heideggerian approach to the consummation of metaphysics in technique, how the processing of objectification of modern Zivilisation is already inscribed in the core of productivist machination of Western metaphysics.
\end{abstract}

Keywords: Philosophy. Technology. Technoscience. Rationality. Metaphysics. Marcuse. Heidegger. 


\section{Introdução}

As reflexões de Marcuse acerca da técnica e da ciência oscilaram entre a admissão de neutralidade e a de comprometimento de ambas com a realidade concreta de específicos projetos político-econômicos de dominação. A despeito de jamais se ter desembaraçado satisfatoriamente dessa tensão no interior de seu pensamento, acabou por prevalecer, contudo, a identificação de Marcuse com a tese de que, como força produtiva, a técnica encerrava um potencial emancipador, muito embora admitisse que a razão técnica, em seu apelo à uniformização como um modus operandi que se impõe a si mesmo - qual uma espécie de Gestell de Heidegger -, carrega consigo já um esquema de dominação, e, portanto, não está circunscrita à forma historicamente determinada de sua expressão sob o capitalismo.

Tal se mostra em suas publicações de maior candência no trato com a temática, que são, basicamente, o texto de 1941 Some Social Implications of Modern Technology e os ensaios reunidos em One-Dimensional Man: Studies in the Ideology of Advanced Industrial Society ${ }^{1}$ - um trabalho dos anos 60. Entre as duas publicações, a segunda é a que condensa o essencial de sua apreciação da técnica, e também a que mais controvérsias e críticas suscitou, pelos motivos que se haverá de registrar.

Assinalável, igualmente, é como se dá a trajetória de Marcuse pelo universo da racionalidade tecnológica desde a chamada fase ontológica, resultante de sua aproximação com Heidegger - que lhe rendeu o que mais tarde

\footnotetext{
${ }^{1}$ Aqui referida na edição brasileira: Herbert Marcuse, A ideologia da sociedade industrial: o homem unidimensional, 1973.
} 
Wolin \& Abromeit classificaram como o marxismo heideggeriano de Marcuse $^{2}$-, passando pela incorporação da Teoria Crítica e a subsequente ruptura com o desconstrucionismo da hermenêutica heideggeriana.

Contra o que chamou de afluência repressiva presente no poder da eficácia do aparato que proscreve todo e qualquer antagonismo entre sujeito e objeto Marcuse afirmou sua confiança na transformação qualitativa da sociedade, na inversão do progresso e na emancipação humana dessa realidade estabelecida. Diferentemente de Heidegger, para quem esse poder que alicia os indivíduos para a gratificação na opulência consiste na própria consumação histórica da metafísica, Marcuse acredita que a transcendência metafísica, restaurada para superação pela razão crítica, poderia vir a confrontar o logos da vida unidimensionada pela instrumentalidade tecnológica.

\section{Técnica, tecnologia e individualismo}

Para além da temática tecnocientífica, que o estudo Some Social Implications of Modern Technology tem o mérito de abordar criticamente, decerto a maior curiosidade desse estudo de 1941 reside no fato de Marcuse ter nele esboçado uma distinção entre técnica e tecnologia a que não daria continuidade no restante de sua obra. O que parecia, pois, tratar-se do núcleo de uma reflexão sistemática não se confirma no próprio texto, e por esse motivo não compreendeu propriamente o rudimento de algo que se desenvolveria posteriormente, ao menos não nos termos de uma bem elaborada e rigorosa

\footnotetext{
${ }^{2}$ Richard Wolin e John Abromeit, Heideggerian Marxism: Herbert Marcuse, 2005.
} 
diferenciação histórico-conceitual em torno da questão técnica versus tecnologia, que porventura houvesse adquirido uma qualificação e um significado muito superiores ao que se esboça ali.

$\mathrm{Na}$ melhor das hipóteses, restringira-se a um insight que permitiu a Marcuse conferir à tecnologia um caráter de processo social e mesmo de modo de produção que abarca a totalidade do aparato característico da era da máquina, e que produz reflexos não apenas na tessitura do pensamento mas também nos padrões de comportamento humano que condizem com seu requisito em matéria de aspirações, necessidades e objetivos. Nesse âmbito, a técnica, instrumentalmente considerada como meio, desponta tão-somente como um fator parcial a serviço do controle e dominação. Mais precisamente,

[...] a tecnologia é tomada como um processo social no qual a técnica propriamente dita (isto é, o aparato técnico da indústria, do transporte, da comunicação) é apenas um fator parcial [...]. A tecnologia, como um modo de produção, como a totalidade dos instrumentos, dispositivos e aparatos que caracterizam a era da máquina, é, assim, ao mesmo tempo, um modo de organizar e perpetuar (ou mudar) as relações sociais, uma manifestação do pensamento prevalecente e dos padrões de comportamento, um instrumento para o controle e a dominação. ${ }^{3}$

Vê-se quão largo é o espectro de ação estruturante das relações sociais que Marcuse reserva à tecnologia, pois ela tanto organiza e condiciona a perpetuação

\footnotetext{
3 “ [...] technology is taken as a social process in which technics proper (that is, the technical apparatus of industry, transportation, communication) is but a partial factor [...]. Technology, as a mode of production, as the totality of instruments, devices and contrivances which characterize the machine age is thus at the same time a mode of organizing and perpetuating (or changing) social relationships, a manifestation of prevalent thought and behavior patterns, an instrument for control and domination." Herbert Marcuse, "Some social implications of modern technology", 1998, p. 41, tradução minha.
} 
do sistema de dominação quanto pode, até mesmo, no campo aberto das virtualidades, alterar o quadro dessas relações que têm lugar no interior do que Marcuse chama de sociedade industrial avançada ou desenvolvida. Seja como for, sua análise da tecnologia não pretende concernir unicamente ao desenvolvimento dos países capitalistas, mas estender-se também aos países da esfera do conhecido socialismo realmente existente, nos quais a gestão burocrática do industrialismo revestira-se de cariz igualmente dominador.

A bem da verdade, se Marcuse trata ali comparativamente pouco das especificidades da ordem tecnológica é porque seu intuito foi o de fazer disso apenas um pano de fundo para pôr a descoberto o processo de emergência de uma forma de racionalidade que ele julga estar contribuindo para tornar impotente o pensamento crítico. Por isso ele avança no sentido de pontuar que a competição que favorece as empresas dotadas de equipamentos industriais mais aperfeiçoados é já o resultado de um processo histórico que transformou a forma racionalizada de autoconservação individual num outro gênero de conduta interessada, que agora se realiza à margem de qualquer consideração racional e guiada por sua própria imediatidade.

Como é sabido, o substrato da eficiência que é característica da moderna produção industrial radica no que Weber qualificou como processo de racionalização da vida em geral, algo que integrou o programa positivista original de Condorcet e Saint Simon e que logo acabaria incorporado ao Ideário das Luzes. ${ }^{4} \mathrm{O}$ culto ao individualismo decorreria, em boa medida, da fixação pela ratio do homem-sujeito cartesiano da modernidade, a ponto de se poder dizer,

\footnotetext{
${ }^{4} \mathrm{Cf}$. Michael Löwy, As aventuras de Karl Marx contra o Barão de Münchhausen, 2000.
} 
como bem observou Rouanet, que um dos traços mais marcantes da filosofia da Ilustração (ao lado de outros, como o cognitivo e o universal) foi a afirmação de sua têmpera violentamente individualista. ${ }^{5}$ Por conseguinte, muitos dos vínculos que atavam o indivíduo à vida comunitária se desfazem, liberando-o para formas de conduta mais hedonistas de autorrealização pessoal.

Marcuse está firmemente convencido de que o indivíduo que é agora promovido por suas realizações pessoais, e exaltado pela revolucionária classe média da era industrial, já não é mais o mesmo daquele da fase liberal do capitalismo, porque a racionalidade não se havia ainda transmutado em racionalidade tecnológica. Cooptado pela eficiência do poder tecnológico, que afeta a valoração do conteúdo crítico da verdade, o indivíduo assim integrado vê a força crítica de sua racionalidade convertida em ajustamento e conformação à vida do apparatum.

\section{Em suma,}

O ponto é que, atualmente, o aparato ao qual o indivíduo deve ajustar-se e adaptar-se é tão racional que o protesto e a liberação individuais parecem não apenas inócuos como também completamente irracionais. O sistema de vida criado pela indústria moderna é um dos mais profícuos, convenientes e eficientes. A razão, uma vez definida nestes termos, transforma-se numa atividade que perpetua este mundo. $\mathrm{O}$ comportamento racional torna-se idêntico a uma factualidade que conduz a uma submissão razoável e, dessa forma, garante que alguém possa se dar bem com a ordem prevalecente. ${ }^{6}$

\footnotetext{
${ }^{5}$ Sérgio Paulo Rouanet, "Dilemas da moral Iluminista", 1992, p. 151.

6 "The point is that today the apparatus to which the individual is to adjust and adapt himself is so rational that individual protest and liberation appear not only as hopeless but as utterly irrational. The system of life created by modern industry is one of the highest expediency, convenience and efficiency. Reason, once defined in these terms, becomes equivalent to an
} 


\section{Racionalidade tecnocientífica da dominação}

O que Marcuse chamou de dependência da ordem objetiva das coisas se poderia tomar como a mais bem-acabada representação daquilo que a lógica econômica converteu numa espécie de imperativo categórico das leis impessoais do mercado. ${ }^{7}$ Nesse contexto, sua alegação de que o "caráter objetável" ${ }^{8}$ do mundo se desvaneceu explicita-se já como a culminância do processo histórico de dominação do homem pelo homem levado a efeito pela tecnociência no interior das sociedades avançadas - num processo que opera auxiliado pelo que Marcuse identificou como uma "introversão da compulsão" .

Isso porque a dominação se teria ela própria tornado mais científica e racional, por meio do emprego mais eficiente dos recursos (materiais e humanos) que propiciam uma cada vez mais elevada e barateada produção, permitindo, desse modo, uma maior difusão e uma incorporação igualmente crescente de novos estratos da sociedade nos resultados do progresso técnico.

E assim, longe de traduzir um avanço em direção à emancipação e à autonomia do pensamento como força crítica definidora de novas possibilidades de orientação do mundo humano da vida, o que se observa é antes o contrário: que essa "organização errônea da sociedade"10 - assimilada como falsa consciência -, em vez de refutada como totalitária ao fim e ao cabo se converte na

activity which perpetuates this world. Rational behavior becomes identical with a matter-offactness which teaches reasonable submissiveness and thus guarantees getting along in the prevailing order." Herbert Marcuse, Op. Cit., 1998, p. 48, tradução minha.

${ }^{7}$ Herbert Marcuse, Op. Cit., 1973, p. 142.

${ }^{8}$ Ibidem, p.146.

9 “[...] introversion of compulsion." Herbert Marcuse, Op. Cit., 1998, p. 51, tradução minha.

${ }^{10}$ Herbert Marcuse, Op. Cit., 1973, p. 146. 
única forma possível de realidade. Daí a importância, segundo ele, de "demonstrar o caráter instrumentalista interno dessa racionalidade científica em virtude da qual ela é tecnologia apriorística, e o a priori de uma tecnologia específica - a saber, tecnologia como forma de controle e dominação social"11.

Com vistas ao entendimento do porquê do ordenamento mais lógico - ou tecno-lógico - desse processo de dominação, é relevante ter em conta, em relação ao texto dos anos 40, o que Marcuse exprime, no dos anos 60, como uma novidade: que "a racionalidade e a manipulação tecnocientíficas estão fundidas em novas formas de controle social"12.

O ponto aí é o de que o pensamento científico e sua aplicação “se movem sob a mesma lógica e racionalidade da dominação"13, por força do esquema intrinsecamente instrumental do método científico, que possibilita a transformação da realidade natural em realidade técnica. Face, então, a esse operacionalismo próprio da ciência, a racionalidade emerge como construção metodológica adaptada à orientação pragmática da ciência.

Segundo Marcuse, foi a racionalidade científica que, ao conceber a natureza em termos de estruturas matemáticas, separou "a realidade de todos os fins inerentes e, consequentemente, dissociou o verdadeiro do bem, a ciência da ética"14. Extorquida em sua finalidade intrínseca pela observação, medição e cálculo, a natureza perde a vitalidade de seu apelo misterioso, de sua disposição como substância independente, e passa então à condição de coisa, de matéria-

\footnotetext{
${ }^{11}$ Ibidem, p .153.

12 Ibidem, p. 144.

${ }^{13}$ Ibidem, p. 152.

${ }^{14}$ Ibidem, p. 144.
} 
prima da tecnicidade. Desse modo, a racionalidade científica, ao emergir como essencialmente neutra, engendra uma nova realidade ideacional, e com isso o mundo objetivo perde aquele seu caráter objetável.

\section{Instrumentalização tecnoeconômica da tecnociência}

A lógica da dominação instrumentalizada pela aplicação da episteme moderna invade a ambiência das atividades produtivas como um todo, plasmando, dessa forma, a totalidade da vida social para estar sujeita à tutela da

racionalidade tecnocientífica. É em vista disso que se pode considerar a tecnociência como a própria força operacional do aparato responsável por essa forma específica de organização da vida social pautada, orientada e conduzida pela funcionalização tecnoeconômica do conhecimento científico que transformou a realidade como um todo num vasto campo experimental de seu domínio. Noutros termos, tecnociência é já aqui, de per se, um estrito modo de produção, e Marcuse é, em boa medida, o precursor desse enquadramento, sobretudo no sentido de o instrumental, como um a priori tecnológico, haver possibilitado a materialização de valores ou sua tradução em tarefas técnicas.

A isso acrescente-se o que Michael Kidd distinguiu, nesse panorama, como sendo um outro aspecto significativo a ter em consideração: que a moderna produção tecnocientífica não se confunde com um modo de produção técnico qualquer, dada sua duplicidade de escopo que envolve não apenas a lucratividade 
(profit-making) para o seu produtor, mas, nomeadamente, o seu funcionar interno como practicality. ${ }^{15}$

Ora, para Marcuse decisivo mesmo teria sido poder levar adiante justamente uma redefinição de valores que, partindo dos elementos técnicos, conduzissem o progresso tecnológico a novos fins. Esses "novos fins, como fins técnicos, operariam tanto no projeto e na construção da maquinaria quanto em sua utilização"16, podendo até mesmo fazerem-se empregar no estabelecimento de novas hipóteses científicas da teoria pura. Assim, "da quantificação das qualidades secundárias a ciência passaria à quantificação dos valores" ${ }^{17}$.

Marcuse sustenta que a afluência nas sociedades de capitalismo avançado dissolveu a força do pensamento crítico, ao integrar seus protagonistas às exigências do aparelho, de sorte que o caráter primariamente liberador da técnica - enquanto medium para a melhoria da qualidade de vida que se efetua pela atenuação do esforço humano e pela produtividade crescente do trabalho que incrementa a riqueza - não constitui o cerne do modo de produção tecnológico, até porque em boa medida isso já foi alcançado.

A questão crucial, então, não reside em providenciar mais meios técnicos para o que já se provou factível. A não ser para fins de sua realização como valor de troca, a mobilização da tecnologia não se dá, primordialmente, para satisfazer necessidades, mas para criá-las, apenas para justificar a gravitação do processo em torno de seu eixo. Eis o leitmotiv do mundo tecnocientífico, esse o da produção

\footnotetext{
${ }^{15}$ Michael Kidd, A Reevaluation of Marcuse's Philosophy of Technology, 2013, p. 11.

${ }^{16}$ Herbert Marcuse, Op. Cit., 1973, p. 214.

${ }^{17}$ Ibidem, p. 215.
} 
pela produção, ou da criação incessante de necessidades desnecessárias. Numa citação recolhida de Thorstein Veblen, Marcuse destacou que a necessidade não é mais a mãe das invenções, mas o contrário: “a invenção é a mãe da necessidade"18.

A violência representada pela natureza humanizada foi, no entender de Marcuse, a precondição para esse modus de existência que internalizou a dominação técnica como dominação do homem pelo homem a partir do que se tornou a racionalidade como tal do aparato. O humano - disse ele - está na desumanização e a escravização (como inserção nessa ordem das coisas), na libertação. ${ }^{19}$ Mais do que nunca, Marcuse está convencido de que essa situação é uma imposição da realidade, e não um enquadramento produzido pela racionalidade científica, a qual é apenas em parte responsável por esse estado de coisas nela justificado pela fusão entre razão prática e teórica.

Ao fazê-lo, fundada no errôneo da organização social, a ciência, como internação da objetivação desumanizadora - isto é, como imperativo do processamento estrutural do quantificável representado pela natureza disponibilizada para exploração pelo cálculo -, elabora o opressivo e o destrutivo do empreendimento das satisfações como racionalidade, conferindo ao sistema uma razão que é, em última instância, a "força sinistra da organização do esquema de aparatos que produz e perpetua a luta pela existência"20.

\footnotetext{
18 "[...] invention is the mother of necessity." Herbert Marcuse, Op. Cit., 1998, p. 47, tradução minha.

${ }^{19}$ Herbert Marcuse, Op. Cit., 1973, cf. p. 143.

${ }^{20}$ Ibidem, p. 142-143.
} 
Em alguns aspectos, notam-se facilmente similaridades entre a concepção de mundo tecnológico de Marcuse e a de Heidegger. É especialmente notável, entre outras, a que diz respeito ao poder do dispositivo (Gestell) do filósofo de Ser e Tempo e ao poder do aparato (apparatus) tecno-político em Marcuse-para quem, em suma, exploração da natureza, manipulação tecnocientífica, racionalidade tecnológica (como processo político) e dominação social compõem um arranjo bem articulado de controle social no âmbito do qual "a técnica se torna a forma universal da produção material" ${ }^{21}$ e a tecnologia, um "veículo de espoliação"22.

\section{A superação da armação do aparato}

Para Marcuse, essa situação toda apresentada é tão execrável quanto anticientífica, porquanto lhe parece que uma razão socialmente restaurada conformaria o mundo de uma outra maneira e num horizonte experimental inteiramente diverso, quiçá dissociado da manipulação abusiva da natureza e da planificação tecnocrática. Numa nova ambientação - eis o wishful thinking de Marcuse - "a ciência chegaria a conceitos de natureza essencialmente diferentes e estabeleceria fatos essencialmente distintos"23. Assim pacificada, na realização da racionalidade do possível de um novo e verdadeiro projeto de realidade, é como uma sociedade racional subverteria a ideia de razão. ${ }^{24}$

\footnotetext{
${ }^{21}$ Ibidem, p. 150.

${ }^{22}$ Ibidem, p. 162.

${ }^{23}$ Ibidem, p. 160.

${ }^{24}$ Ibidem, p. 160.
} 
No fundo, Marcuse tenciona confrontar e reverter a determinação aprioristicamente técnica da ciência subsumida no poder do aparato. Reconhecea, entretanto, porque, antes de mais nada, aceita os supostos do materialismo histórico relativamente às vicissitudes responsáveis pelo desvirtuamento da razão convertida em racionalização processadora.

Marcuse supõe que a racionalidade originalmente norteadora da ciência esteve imbuída de um outro desígnio, mais afeito à promoção do ideário humanista, libertário e emancipador. A dimensão metafísica - até então assimilada como campo genuíno do pensamento racional - transmuta-se em "irracional e anticientífica"25, o que equivale a admitir que "a razão teórica, permanecendo pura e neutra, entrou para o serviço da razão prática" ${ }^{26}$. Como se percebe, faz falta aqui a Marcuse a clarificação realizada por Heidegger acerca do cunho produtivista da metafísica ocidental em seu fazer violento, isto é, em seu modo infringente de provocar o aparecimento (Hervor-bringen) das coisas, que foi o que tornou possível o industrialismo tecnológico moderno.

Não obstante, a obra de Marcuse conserva-se incrivelmente relevante para explicitar, mormente nos dias de hoje, a servidão voluntária associada ao pensamento único do homem econômico global. Evidentemente, quer pela complexidade da temática que arrostou, quer pela heterodoxia de sua análise num contexto histórico particularmente efervescente e bastante ideologizado, a obra de Marcuse acabaria por ensejar toda sorte de reação. Michael Kidd, a propósito, sublinha o aspecto multidimensional da abordagem da tecnologia na

\footnotetext{
${ }^{25}$ Herbert Marcuse, Op. Cit., 1973, p. 165.

${ }^{26}$ Ibidem, p. 154.
} 
obra de Marcuse para justificar muitos dos mal-entendidos a que deu lugar. Basicamente, o "forte pessimismo de O Homem Unidimensional era comumente tomado como uma forma de determinismo no qual os agentes humanos foram reduzidos a meros efeitos de causas tecnológicas mais profundas"27.

Nota-se algo do gênero, de fato, ao longo dessa obra capital de Marcuse, em passagens que aludem à utilização técnica do homem, à tecnologia como o grande veículo de espoliação, ou ainda, paradoxalmente, à tecnologia pensada como a grande racionalização da não-liberdade do homem, demonstrando, com isso, "a impossibilidade técnica de a criatura ser autônoma, de determinar sua própria vida"28. Há aqui, ineludivelmente, reverberações de Heidegger. No mais, não é de estranhar que Marcuse desponte como um determinista tecnológico - não menos, nessa linha, que o próprio Heidegger. Quando não mesmo, de resto - a exemplo também de Heidegger -, como catastrofista, ao aventar que "a força libertadora da tecnologia - a instrumentalização das coisas - se torna o grilhão da libertação, a instrumentalização do homem"29.

Entretanto, diferentemente de Heidegger, para quem a questão da técnica extrapola uma intervenção de natureza política, Marcuse acredita que a armação da racionalidade tecnológica ou tecnocientífica pode ser socialmente modificada, superada ou revertida em sua tendência que fez do progresso técnico, por um lado, uma forma de regressão e, por outro, da experimentação

\footnotetext{
27u[...] the strong pessimism of One-Dimensional Man was often taken as a form of technological determinism in which human agents were reduced to the mere effects of deeper technological causes". Michael Kidd, Op. Cit., p. 16, tradução minha.

${ }^{28}$ Herbert Marcuse, Op. Cit., 1973, cf. p. 152-162.

${ }^{29}$ Ibidem, p. 155.
} 
científica uma prática inerentemente ligada aos "planos do establishment econômico, político e militar"30. Nessas circunstâncias,

uma mudança poderia ser imaginada apenas como um evento no desenvolvimento da própria ciência, mas tal desenvolvimento científico somente pode ser esperado como resultado de uma ampla mudança social. O necessário é nada menos que uma completa transvaloração dos objetivos e necessidades, a transformação das políticas e instituições repressivas e agressivas. A transformação da ciência é imaginável apenas em um ambiente transformado; uma nova ciência exigirá um novo clima, em que novos experimentos e projetos serão sugeridos ao intelecto por novas necessidades sociais ${ }^{31}$.

Aí está, então: Marcuse pretende que uma mudança no desenvolvimento da ciência só é factível num ambiente social, político e cultural já modificado, regido por novas necessidades que não as habitualmente requeridas pelo ideáriofetiche do crescimento econômico (growth fetishism ${ }^{32}$ ) e do consumismo desenfreado (overconsumption) vinculados ao liberalismo econômico que está transformando a Terra em um inferno..$^{33}$

\footnotetext{
${ }^{30}$ Herbert Marcuse, "A responsabilidade da ciência", 2009a, p. 160.

${ }^{31}$ Ibidem, p. 162-163.

${ }^{32}$ Expressão usada por Clive Hamilton (Growth Fetish. Sydney: Allen and Unwin, 2003), para criticar, justamente, a obsessão da imensa maioria dos países com o insano crescimento econômico a qualquer preço e com o estímulo, disso derivado, à compulsão consumista da free market ideology.

${ }^{33}$ Cf. Herbert Marcuse, Eros e civilização, 1975, p. 13.
} 


\section{Historicidade concreta da teoria}

De um modo geral, pode-se dar como certo que Marcuse buscou sempre um lastro para fundar a relação homem-mundo que pudesse dar conta da destinação final dos processos de trabalho. Esteve sempre empenhado em facultar à existência uma saída racional fundada no mundo da vida real. A esse respeito, sua aproximação com Heidegger, em fins dos anos 20 do século passado, dá-se já num plano a partir do qual imaginou poder encontrar na fenomenologia a base de que precisava para uma sedimentação ontológica de seu projeto existencial originário. A bem da verdade, o que queria mesmo era dar à fenomenologia uma compleição revolucionária.

Vislumbrou, portanto, no pensamento de Heidegger um novo começo, precisamente uma fundação concreta de uma nova perspectiva para a filosofia acadêmica convencional. É que Heidegger falava, entre outras coisas, de indivíduos reais, de entes históricos em sua historicidade, de vida material etc., dando assim à sua noção de concretude um sentido muito próximo ao da visão marxiana. Nas palavras do próprio Marcuse:

\footnotetext{
Para mim e meus amigos, o trabalho de Heidegger surgiu como um novo começo. Nós experimentamos seu livro (Ser e Tempo) e suas conferências cujas transcrições obtínhamos - como, finalmente, uma filosofia concreta: aqui se falava de existência [Existenz], de nossa existência, de medo e cuidado e tédio e assim por diante. Também experimentamos uma emancipação "acadêmica": a interpretação de Heidegger da filosofia grega e do idealismo alemão, que nos ofereceu uma nova perspectiva dos textos antigos, fossilizados. ${ }^{34}$
}

\footnotetext{
34 “To me and my friends, Heidegger's work appeared as a new beginning: we experienced his
} book [Being and Time] (and his lectures, whose transcripts we obtained) as, at long last, a concrete 
Realmente, muito se pode aduzir em defesa da importância, do significado e do alcance revolucionário do pensamento filosófico de Heidegger que muito impressionou Marcuse. Para começar, o próprio título da obra One Dimensional Man não passa, segundo Steiner, de "uma variante da noção mais abrangente do 'ser-eles' [theyness] de Heidegger"35. ${ }^{36}$ No mais, "a ideia de que o Dasein pode transcender a alienação através da autenticidade pessoal, e que a autenticidade verdadeira implica envolvimento ativo com os outros, será uma noção seminal para Herbert Marcuse" ${ }^{37}$.

Ademais, na altura em que Sein un Zeit veio a público, em 1927, o costumeiro procedimento positivista que consistia (e ainda, infelizmente, consiste) em cultuar a imediatidade do fato - como se representasse o veredito da objetividade supostamente estabelecida pela neutralidade da teoria científica sofre um duro golpe com a analítica existencial [Existenzphilosophie] de

philosophy: here there was talk of existence [Existenz], of our existence, of fear and care and boredom, and so forth. We experienced an 'academic' emancipation: Heidegger's interpretation of Greek philosophy and German idealism, which offered us new insights into antiquated, fossilized texts." Herbert Marcuse, "Postscript: My Disillusionment with Heidegger", 2005a, p. 176, tradução minha.

35 “[...] a variant on Heidegger's more far-reaching notion of 'theyness'." George Steiner, Martin Heidegger, 2013, p. 139, tradução minha.

${ }^{36}$ Por oposição ao que sugerem vocábulos como oneness, one's own self ou being one's own master, que remetem ao ser-nós próprios [eigen (own)] ou ao ser-si-mesmo (Selbstsein) na autenticidade (Eigenlischkeit) do Dasein, theyness, empregado por Steiner, guarda, pois, no contexto, relação com a alienação que é característica do Das Man heideggeriano em sua quotidianidade, ou do Dasein em sua mediania (Durchsnittlichkeit); é, enfim, o eu alienado de si mesmo, pertencente aos outros, enredado na inautenticidade (Uneigentlichkeit), que cedeu sua existência ao ser-eles (theyness) de uma alteridade sem forma (Cf. p. 97).

37 "This idea -that Dasein can transcend alienation through personal authenticity, that true authenticity entails active involvement with others- will be a seminal notion for Herbert Marcuse." Ibidem, p. 110, tradução minha. 
Heidegger, que agora dá lugar ao Dasein, à concretude do homem em sua existência como ponto de partida, e não mais àquelas relações triviais de causalidade em cujo âmbito as pessoas são tratadas como coisa entre coisas. Ao fazer isso, Heidegger colocava não a objetividade, mas a própria realidade humana no centro da perspectiva fenomenológica. Indiscutivelmente, essa mudança representou muito para Marcuse, uma vez que a Filosofia de Heidegger operava uma importante ruptura nesse quadro metodológico, capaz de proporcionar, na visão de Wolin \& Abromeit, "a alavancagem conceitual para superar a orientação reificadora da ciência tradicional"38.

Mas em que pese o fato de a trajetória intelectual e acadêmica de Marcuse ter sido grandemente influenciada por sua convivência com Heidegger - tanto no que se refere à abertura para a compreensão do caráter histórico e real da existência, quanto no que respeita, mais tarde, à compreensão da falta de neutralidade da ciência e da tecnologia -, é notório que $\operatorname{Marx}^{39}$ acabaria por se

38 "[...] the conceptual leverage to overcome the reifying orientation of traditional science." Richard Wolin e John Abromeit, Op. Cit., 2005, p. XV, tradução minha.

${ }^{39}$ Especialmente a leitura dos Manuscritos Econômico-Filosóficos foi decisiva. Nas palavras do próprio Marcuse, "the publication of the Economic and Philosophical Manuscripts written by Marx in 1844 must become a crucial event in the history of Marxist studies" (Herbert Marcuse, "'New Sources on the Foundation of Historical Materialism", 2005b, p.86). Ainda sobre os Manuscritos, comentou acerca de sua importância já por ocasião de sua convivência com Heidegger, entre 1928 e 1932: "Durante todo ese tiempo yo había leído y releído a Marx, y entonces tuvo lugar el descubrimiento de los Manuscritos de Economia y Filosofía. Este fue probablemente el giro. Aquí había un nuevo Marx que era realmente concreto y que al mismo tiempo se elevaba por encima del petrificado y enmohecido marxismo teórico y práctico de los partidos. Y a partir de ese momento el problema Heidegger versus Marx dejó de ser un problema para mí" [Jürgen Habermas, "Diálogo con Herbert Marcuse (1977)", 1975, p. 239]. Disso não decorre, entretanto, que Marcuse tenha considerado o marxismo como uma teoria científica rigorosa ou um sistema de verdade que devesse ser tomado de forma acrítica e doutrinal. Longe disso. Antes se lhe afigurou como uma abordagem metodológica, uma ferramenta de trabalho para realizar a crítica histórica do capitalismo a partir de uma teoria da ação social. Marcuse tem ciência de que o 
tornar o pensador mais emblemático na realização do conjunto da obra de Marcuse, para o que terá sido decisiva sua posterior vinculação à Escola de Frankfurt.

O modo de existência humana que Marcuse tomaria para si é, sabidamente, o da materialidade concreta do ser social, e não mais aquele da historicidade inicial da fenomenologia que lhe chegou através de Heidegger ${ }^{40}-$ mas não exclusivamente. Como ele mesmo disse em Negations, "desde Dilthey as várias tendências da Lebensphilosophie (filosofia da vida) e do existencialismo preocupavam-se com a historicidade concreta da teoria"41. Mesmo a fenomenologia - acrescenta ali - fora também "concebida como a filosofia da objetividade (Sachlichkeit) material concreta" ${ }^{42}$, e isso, em princípio, pareceu-lhe admiravelmente aceitável. Mas não o bastante, porque lhe ficaria restando a matriz dos componentes antropológico e dialético de uma outra historicidade.

Não demoraria muito para que Marcuse viesse a dar às suas reflexões um novo direcionamento, provocado não apenas pelo contato com a Teoria Crítica -

proletariado marxista não é o representante da liberdade (Cf. Herbert Marcuse, Op. Cit.,1975, p. $16)$.

${ }^{40}$ Sobre Heidegger, numa entrevista concedida a Olafson, Marcuse comentou: "We saw in Heidegger what we had first seen in Husserl, a new beginning, the first radical attempt to put philosophy on really concrete foundations-philosophy concerned with human existence, the human condition, and not with merely abstract ideas and principles" (Herbert Marcuse, "Heidegger's Politics: An Interview", 2005c, p. 165-166).

41 "Since Dilthey, the various trends of Lebensphilosophie (philosophy of life) and existentialism have concerned themselves with the concrete 'historicity' of theory." Herbert Marcuse, Negations: essays in critical theory, 2009b, p. 57, tradução minha.

42 “[...] phenomenology, too, as was mentioned above, was conceived as the philosophy of concrete material objectivity (Sachlichkeit)." Ibidem, p. 57, tradução minha. 
com o seu ingresso, a partir de 1933, na Escola de Frankfurt ${ }^{43}$-, mas também pelo que lhe chegaria através de Luckács: a ontologia marxiana de base objetiva para articular o sentido do homem como ser social na concretude da existência. Marcuse crê poder realizar, dessa forma, um novo trânsito da filosofia para a práxis transformadora do mundo da vida.

Não por acaso, as divergências com Heidegger se dariam especialmente em torno da noção de historicidade, que a Marcuse parecia agora abordada de um modo que deixara de lhe convir, desde que vira na ontologia existencial um turning point na história da filosofia. Distancia-se, então, do projeto heideggeriano da hermenêutica desconstrucionista, por julgar que talvez aquilo que esta lhe tinha a oferecer não só não correspondia mais ao que buscava, como até mesmo já se lhe passara a afigurar-se como uma variante do transcendentalismo.

Tudo isso porque imaginou poder fazer da filosofia de Heidegger uma espécie de ativismo político ou mesmo um guia para qualquer coisa do gênero, algo que, em verdade, este pensador não concebeu, ao menos não em termos, propriamente, de uma mediação material. Ao salientar que a existência era em si mesma histórica, carregada de tradições e de possibilidades futuras, Heidegger, com a noção de futuridade, deu, assim, "um componente ativista à historicidade" ${ }^{44}$. Marcuse a tomou inicialmente por seu valor de face, em sua literalidade, interpretando, à sua maneira, a noção de concretude em Heidegger

\footnotetext{
${ }^{43}$ Sob a influência da Escola de Frankfurt, segundo Andrew Feenberg (Heidegger and Marcuse: the catastrophe and redemption of History, 2005, p. 86.), Marcuse desenvolveria, entre outros, os conceitos de "racionalidade tecnológica e unidimensionalidade".

44 "[...] an activist component to historicity." Richard Wolin e John Abromeit, Op. Cit., 2005, p. XIX, tradução minha.
} 
como prelúdio de uma práxis social emancipatória. Não que ela não o seja, convenhamos, mas só que de um outro jaez.

Com efeito, a interpretação antropológica da natureza humana, baseada no que Marx postulou como estando associada à atividade produtiva e ao trabalho, enquanto constituinte da condição humana, foi o que mais impactou Marcuse, e reforçou nele a convicção de que a historicidade em Heidegger carecia de concreção, tanto quanto a sua essência da técnica, que lhe pareceu reificada, hipostasiada como destino. Marcuse - que admite não haver compreendido certas coisas nos escritos de Heidegger - tem a impressão de que os conceitos heideggerianos de técnica e tecnologia "são tratados como forças em si-mesmas, apartadas do contexto das relações de poder que as constituem e que determinam seu uso e função"45.

Na perspectiva de Marcuse, a tecnologia figura como extensão e incorporação do potencial instrumental do humano que não pode dizer respeito a uma existência à margem dos imperativos imediatos da produção da vida material. Assim, ao endossar a compreensão marxiana da natureza humana, Marcuse compartilha das fundações filosófico-antropológicas dessa teoria relativamente à centralidade do trabalho na constituição da condição humana, sem, contudo, abdicar da elaboração de sua versão crítica do marxismo com vistas a conservar dele o potencial político-revolucionário de suas promessas libertárias.

45 “ $[. .$.$] they are treated as 'forces in-themselves', removed from the context of power relations in$ which they are constituted and which determine their use and their function." Herbert Marcuse, Op. Cit., 2005c, p. 168, tradução minha. 
A propósito, e a título apenas de um breve contraponto, vale salientar que, enquanto para Marx e Marcuse as habilitações técnicas têm a ver com a construção do que significa ser humano, para Heidegger significam bem outra coisa, porque ele as remete, no essencial, ao esquecimento do ser do homem, com todas as terríveis implicações resultantes do predomínio da tecnicidade no modo de pensar e de viver. Com Heidegger, pôde-se finalmente perceber que esse esquecimento esteve desde sempre radicado no âmago do ideário humanista, e isso explica o porquê de seu retumbante fracasso. Isto posto, e falando mais precisamente, diz Sloterdijk (que, todavia, não endossa inteiramente a crítica endereçada por Heidegger ao humanismo),

para que exaltar novamente o ser humano e seu autorretrato filosófico padrão como solução no humanismo, se a catástrofe do presente acaba de mostrar que o problema é o próprio ser humano, com seus sistemas metafísicos de autoelevação e autoexplicação ${ }^{46}$ ?

E foi nesse plano, diga-se de passagem, que Heidegger considerou a alienação em Marx análoga a um exílio, pois o ser foi afastado de sua morada e abandonado no mundo, entregue ao ente que é agora - como expressão distópica do humanismo - o homem convertido na besta de trabalho que tudo calcula e em tudo vê apenas uma disposição de meios para a desmesura do incremento de valor, para a realização de algo em si destituído de um horizonte de significação que não o do incondicionado da vontade de poder da técnica e do gigantismo de sua produção. A exemplo, então, do que se passa com qualquer outra vertente do

\footnotetext{
${ }^{46}$ Peter Sloterdijk, Regras para o parque humano: uma resposta à carta de Heidegger sobre o humanismo, 2000, p. 23.
} 
humanismo (existencialista, cristão etc.), também a do marxismo, garantiu Heidegger na Briefüber den Humanismus, "coincide no fato de que a humanitas do homo humanus se determina com base na perspectiva previamente estabelecida de uma interpretação da natureza, história, mundo e fundamento do ente em sua totalidade" ${ }^{47}$.

Nesse sentido, a questão do determinismo econômico, como fundamento da natureza humana em Marx, não modifica o essencial da questão que se quer aqui, en passant, levantar, qual seja: que nem Marx e, até certo ponto, nem mesmo Marcuse escapam às artimanhas metafísicas da entificação do humano como coisa objetivamente dada. Para Marx, declarou Heidegger, "ser é processo de produção", e isto corresponde à ideia de "representação que ele recebe da metafísica, baseada na interpretação hegeliana da vida como processo" ${ }^{48}$. Portanto, "o conceito prático de produção pode apenas existir apoiado numa concepção de ser decorrente da metafísica" ${ }^{49}$.

Isso revela que, mesmo como crítico do marxismo, e tendo podido conviver com Heidegger, de quem acabaria por se afastar (de um modo mais físico que intelectual), Marcuse aceita a injunção do materialismo que projeta o mundo do humano como matéria de cálculo e de manipulação e, por conseguinte, como meio para um fim que ambos, Marx e Marcuse, viam como possível de ser politicamente transformada a partir da superação da lógica

\footnotetext{
${ }^{47}$ Martin Heidegger, Carta sobre el humanismo, 2006, p. 23.

48 "For Marx, being is the production process. This is the representation that he receives from metaphysics, on the basis of Hegel's interpretation of life as process." Martin Heidegger, Four seminars: Le Thor 1966, 1968, 1969, Zähringen 1973, 2003, p. 52, tradução minha.

49 "The practical concept of production can only exist on the basis of a conception of being stemming from metaphysics." Ibidem, p. 52, tradução minha.
} 
econômico-política da reprodução incessante do mais-valor como uma finalidade per se, porque é aí, na esfera econômica, que desemboca aquela sobredeterminação gestelliana da diretriz calculadora da técnica. No fundo, Heidegger cuidou de demonstrar que o producionismo consistiu no erro capital da metafísica ocidental, e isso de alguma maneira não deixou de reverberar nem mesmo num marxista-heideggeriano como Marcuse - quanto mais não fosse pelo que se sabe: que "a metafísica pensa o homem a partir da animalitas e não em função de sua humanitas" ${ }^{\prime 50}$.

\section{A metafísica restaurada}

A Marcuse também inquieta que a humanitas do homem - ao contrário de sua animalitas - não se tenha ainda traduzido em realidade, porque o progresso da civilização, circunscrito ao avanço técnico, "exige modos de pensar operacionais e traduzíveis em atitudes apropriadas para aceitar a racionalidade produtiva dos sistemas sociais dados" ${ }^{\prime 1}$, os quais se reproduzem emulados pela concorrência econômica e pelas forças que, nessa esfera, Marcuse presume serem as mantenedoras da "vida desse todo" ${ }^{52}$. Obviamente, conforme ressaltado, Marcuse tenciona extrair implicações normativas da crítica ao existente com vistas a novos planos de vida. E é nesse âmbito que se percebem certas ambiguidades dele no trato com a questão da metafísica.

\footnotetext{
${ }^{50}$ Martin Heidegger, Op. Cit., 2006, p. 27.

${ }^{51}$ Herbert Marcuse, "Comentários para uma redefinição da cultura", 2001b, p. 84.

${ }^{52}$ Herbert Marcuse, "Sobre o caráter afirmativo da cultura”, 2001c, p. 24.
} 
No texto de 1961, The Problem of Social Change in the Technological Society, embora considere que "a racionalidade totalitária do apparatus técnico-político" - o Gestell marcusiano, por assim dizer - conspira contra qualquer possibilidade de mudança porque "embota o reconhecimento de que os fatos são construídos, mediados pela Subjetividade", e que contêm sua negatividade, Marcuse, ao mesmo tempo, admite que "a capacidade de avaliar alternativas requer a liberdade de ir além dos fatos e das operações definidas pelos fatos" 53 . O pensar que representa um empecilho a uma tal forma de libertação é ele mesmo, diz Marcuse, irracional, metafísico e ilusório. Mais grave: Marcuse supõe que a luta contra a metafísica liquida a metafísica e promove a submissão ao que é. ${ }^{54}$

Poucos anos depois, em 1965, no já aqui citado Comentários para uma redefinição de cultura, Marcuse alude - com algumas ressonâncias heideggerianas - a "que o homem não é efetivamente ele mesmo, nem está em seu próprio elemento, mas sim submetido à heteronomia"55, e que, a despeito do totalitarismo da técnica, acredita que a humanidade alcançou um estágio histórico capaz de criar um mundo de paz - um mundo sem exploração, miséria e medo"56. Para isso haveria que se converter a civilização em cultura. Taxativamente, acrescenta, "nenhum modo de pensar pode fazer isto, mas o pensamento pode contribuir para o desenvolvimento daquela consciência que é um pressuposto da libertação"57. Libertação que é, sobretudo, a do "pensamento

\footnotetext{
53 “The politico-technical apparatus and its totalitarian rationality [...] blunt the recognition that facts are made, mediated by Subjectivity [...] the ability to evaluate the alternatives requires the freedom to go beyond the facts and beyond the operations defined by the facts." Herbert Marcuse, "The Problem of Social Change in the Technological Society", 2001a, p. 55, tradução minha.

${ }^{54}$ Ibidem, cf. p. 56.

${ }^{55}$ Herbert Marcuse, Op. Cit., 2001b, p. 81.

${ }^{56}$ Ibidem, p. 90.

${ }^{57}$ Ibidem, p. 99.
} 
teórico de seus vínculos com uma práxis opressora" ${ }^{58}$; libertação que é, outrossim, essencialmente, a libertação da própria ciência da tecnificação que subjuga a natureza e o próprio homem, e que faz dela um veículo de investigação a serviço da produtividade que é exploração, da manipulação que é violência e da criação que é, igualmente, uma destruição.

Marcuse está certo de que é possível, portanto, resgatar a pureza original da ciência. Disse ele:

A racionalidade científica pura inclui a possibilidade real de suprimir a privação e a injustiça no mundo inteiro. Não se trata de anular ou reduzir a ciência, mas de libertá-la dos senhores que a ciência mesma contribuiu para estabelecer. E essa libertação não seria um acontecimento externo que deixaria intacto o empreendimento científico em sua estrutura: ela concerne inteiramente ao próprio método científico, à experiência científica e à projeção da natureza. Numa sociedade racional e humana a ciência teria uma nova função, e essa função poderia tornar necessária uma reconstrução do método científico ${ }^{59}$.

Nessa reconstrução, aquilo que a ciência rechaça - a historicidade concreta - se apresenta, então, para Marcuse, como transcendência metafísica, necessária, por assim dizer, a uma viragem do processo, para o que o pensamento - como em Heidegger - é primordial. Até porque, de acordo com Marcuse, o pensamento nem sempre foi e não é prontamente razão técnica - pelo menos não até Descartes, quando então se desgarra, segundo ele, da práxis social. ${ }^{60}$ Assim,

\footnotetext{
${ }^{58}$ Ibidem, p. 100.

${ }^{59}$ Ibidem, p. 103.

${ }^{60}$ Cf. Herbert Marcuse, Op. Cit., 1973, p. 32.
} 
“a dimensão metafísica, antes um campo genuíno do pensamento racional, torna-se irracional e anticientífica" ${ }^{\prime 61}$.

A fim de esclarecer melhor este ponto, vale a pena fazê-lo no contexto de uma passagem de One-Dimensional Man particularmente reveladora de uma certa afinidade entre Marcuse e Heidegger, que é quando o primeiro reivindica que "a realidade tecnológica seria não apenas um requisito, mas também o fundamento lógico para transcender a realidade tecnológica"62. Ora, não há como não recordar aqui do poema de Hölderlin invocado por Heidegger, ao final de Die Frage nach der Technik, para nos lembrar de que onde reside o perigo medra também o que pode nos salvar. ${ }^{63}$ Para Marcuse, é perfeitamente admissível promover-se um conserto do que se desencaminhou no curso da razão esclarecedora - agora convertida e hegemonizada como instrumentalidade no âmbito da racionalidade científica - por meio do restauro da relação tradicional entre a ciência e a metafísica, em sua propriedade ontológico-humanística, na base de cuja reaproximação as ideias estariam novamente em condição de, finalmente, elaborar uma nova episteme, uma nova construção cognitiva da realidade, dessa vez inteiramente em desacordo com o sedimentado pelo experimentalismo operatório das ciências positivas em seu compromisso com uma existência não verdadeira e livre.

Não sem alguma aparente inconsistência, a transformação científica do mundo assim produzida acarretaria a própria supressão do caráter metafísico da ideação transformadora. Afinal, se “o projeto tecnológico compreende um

\footnotetext{
${ }^{61}$ Herbert Marcuse, Op. Cit., 2001b, p. 165.

${ }^{62}$ Herbert Marcuse, Op. Cit., 1973, p. 214.

${ }^{63}$ Martin Heidegger, "A questão da técnica”, 2007.
} 
rompimento com a racionalidade tecnológica prevalecente", então "o rompimento depende, por seu turno, da existência continuada da própria base tecnológica" ${ }^{64}$. Ainda: subsidiariamente, "se a realização histórica da ciência e da tecnologia possibilitou a tradução de valores em tarefas técnicas", então o que está em jogo, neste caso, "é a redefinição dos valores em termos técnicos" 65 .

Nesse tocante, Marcuse por certo se situa nas antípodas de Heidegger, para quem a ameaça extrema reside já na forma técnica de pensar e de agir encerradas no Gestell da era tecnológica. O pensar técnico, enquanto pensamento da ação eficaz que se traduz em plano calculado, em forma segura de comando do formulável na produção e execução, é a própria configuração da atitude tecnológica contemporânea, o sine qua non operatório da maneira pela qual o mundo é cientificamente compreendido e apropriado. O mero existir ao modo de ser ciência, que implica o exercício de uma ontologia, de um modo de apreender o ser (e de negá-lo, ao mesmo tempo), dá-se já no interior de uma determinação técnica do pensar, que, na modernidade, fomenta o projeto de controle do mundo mediante a posicionalidade geral do ente concebido como presença constante.

A Heidegger, certamente, soaria despropositado pretender sua suplantação por meio de uma pregnância de valores que pudessem apontar para um novo conteúdo de mundo, isto é, para uma ruptura com a racionalidade totalizante da técnica dando-se tecnicamente, a partir dos componentes supostamente neutrais, porque apenas operativos, da marcha tecnológica. Já no entender de Marcuse, o ser-assim metafísico e o ser-instrumento não se co-

\footnotetext{
${ }^{64}$ Herbert Marcuse, Op. Cit., 1973, p. 214.

${ }^{65}$ Ibidem, p. 214.
} 
pertencem, e uma desejável reorientação do progresso se mostra factível se "as ideias antes metafísicas de libertação"66 se transmutarem no próprio objeto da ciência e do método científico, conduzindo, dessa forma, a uma "revalidação da metafísica com base na transformação científica e tecnológica" ${ }^{67}$. Em suma, aqui é como se a metafísica, em Marcuse, abrigasse qualquer coisa como uma razão pré-tecnológica, crítica, capaz de propiciar o fulcro de um contexto experimental diverso, que possibilitasse à ciência elaborar uma outra episteme para a natureza, com base na qual se pudessem então estabelecer fatos essencialmente novos.

\section{Considerações finais}

Em aspectos fundamentais do universo da técnica, Marcuse se move numa direção bem diversa da de Heidegger, a começar por sua preocupação com o ativismo político, que nele se justifica com vistas, notadamente, à realização de um projeto de liberação da razão crítica de seu confinamento pela racionalidade tecnológica. Segundo ele, essa forma de racionalidade estabelece padrões de julgamento e fomenta atitudes que tornam os homens disponíveis para introjetar o dictum do aparato. Sob o signo dessa sujeição, que inibe as formas de contestação e protesto, a racionalidade crítica é neutralizada em sua potência negadora como força de oposição ao estado opressivo da realidade técnica do mundo.

\footnotetext{
${ }^{66}$ Ibidem, p. 215.

${ }^{67}$ Ibidem, p. 220.
} 
Sociedade Unidimensional foi a designação que Marcuse aplicou às sociedades tecnologicamente avançadas para caracterizar a força homogeneizadora ou totalitária da razão técnica em seu expediente de manipulação de necessidades e interesses, a ponto de prefixar a vida dos indivíduos à ordem social estabelecida. Esse processo de manipulação se dá num nível tal que, para Marcuse, torna até mesmo confortável a falta de liberdade, e assim faz o funcionamento de tudo parecer suave através da satisfação dos indivíduos na superfluidade. É o que ele chamou de euforia na infelicidade. Infelicidade que, evidentemente, não é criticamente apreendida pelos indivíduos já devidamente conformados e assimilados ao meio social produtor de mercadorias com as quais se identificam e nas quais se reconhecem. É esse, enfim, o modo pelo qual a irracionalidade se torna racional e coage o pensamento negativo a um recolhimento.

\section{Referências}

FEENBERG, Andrew. Heidegger and Marcuse: the catastrophe and redemption of History. New York: Routledge, 2005.

HABERMAS, Jürgen. Diálogo con Herbert Marcuse (1977). In: HABERMAS, Jürgen. Perfiles filosófico-políticos. Tradução: Manuel J. Redondo. Madrid: Taurus, 1975.

HAMILTON, Clive. Growth Fetish. Sydney: Allen and Unwin, 2003. 
HEIDEGGER, Martin. Four seminars: Le Thor 1966, 1968, 1969, Zähringen 1973. Tradução: Andrew Mitchell \& François Raffoul. Bloomington: Indiana University Press, 2003.

HEIDEGGER, Martin. Carta sobre el humanismo. Tradução: Helena Cortés y Arturo Leyte. Madrid: Alianza Editorial, 2006.

HEIDEGGER, Martin. A questão da técnica. Tradução: Marco A. Werle. Scientiæ Studia, São Paulo, v. 5, n. 3, 2007, p. 375-398.

KIDD, Michael. A Reevaluation of Marcuse's Philosophy of Technology. 2013. $231 \mathrm{f}$. Tese (Doutorado em Filosofia) - University of Tasmania, Australia.

LÖWY, Michael. As aventuras de Karl Marx contra o Barão de Münchhausen. 7. ed. Tradução: Juarez Guimarães e Suzane F. Léwy. São Paulo: Cortez, 2000.

MARCUSE, Herbert. A ideologia da sociedade industrial: o homem unidimensional. 4. ed. Tradução: Giasone Rebuá. Rio de Janeiro: Zahar, 1973.

MARCUSE, Herbert. Eros e civilização. 6. ed. Tradução: Álvaro Cabral. Rio de Janeiro: Zahar, 1975.

MARCUSE, Herbert. Some social implications of modern technology. In: KELLNER, Douglas (ed.). Collected Papers of Herbert Marcuse: Technology, War and Fascism. v. 1. Londres; Nova York: Routledge, 1998.

MARCUSE, Herbert. The Problem of Social Change in the Technological Society. In: KELLNER, Douglas (ed.). Collected Papers of Herbert Marcuse: Towards a critical theory of society. v. 2. Londres; Nova York: Routledge, 2001a. 
MARCUSE, Herbert. Comentários para uma redefinição da cultura. Tradução: Robespierre de Oliveira. In: MARCUSE, Herbert. Cultura e Sociedade. São Paulo: Paz e Terra, 2001b.

MARCUSE, Herbert. Sobre o caráter afirmativo da cultura. Tradução: Wolfgang Leo Maar. In: MARCUSE, Herbert. Cultura e psicanálise. São Paulo: Paz e Terra, 2001c.

MARCUSE, Herbert. Postscript: my disillusionement with Heidegger. In: WOLIN, Richard; ABROMEIT, John (Orgs.). Heideggerian Marxism: Herbert Marcuse. Lincoln; Londres: University of Nebraska Press, 2005a.

MARCUSE, Herbert. New Sources on the Foundation of Historical Materialism. In: WOLIN, Richard; ABROMEIT, John (Orgs.). Heideggerian Marxism: Herbert Marcuse. Lincoln; Londres: University of Nebraska Press, 2005b.

MARCUSE, Herbert. Heidegger's Politics: An Interview. In: WOLIN, Richard; ABROMEIT, John (Orgs.), Heideggerian Marxism: Herbert Marcuse. Lincoln; Londres: University of Nebraska Press, 2005c.

MARCUSE, Herbert. A responsabilidade da ciência. Scientiæ Studia, São Paulo, v. 7, n. 1, p. 159-164, 2009a.

MARCUSE, Herbert. Negations: essays in critical theory. Tradução: Jeremy J. Shapiro. Londres: Mayffybooks, 2009b.

ROUANET, Sérgio Paulo. Dilemas da moral Iluminista. In: NOVAES, Adauto. Ética. São Paulo: Companhia das Letras/Secretaria Municipal de Cultura, 1992. 
SLOTERDIJK, Peter. Regras para o parque humano: uma resposta à carta de Heidegger sobre o humanismo. Tradução: José O. A. Marques. São Paulo: Estação Liberdade, 2000.

STEINER, George. Martin Heidegger. Nova York: Open Road Integrated Media, 2013.

WOLIN, Richard. Los hijos de Heidegger: Hannah Arendt, Karl Löwith, Hans Jonas y Herbert Marcuse. Tradução: María Condor. Madrid: Ediciones Cátedra, 2003.

WOLIN, Richard; ABROMEIT, John. Heideggerian Marxism: Herbert Marcuse. Lincoln; Londres: University of Nebraska Press, 2005.

\section{Referência para citação deste artigo}

NASCIMENTO, Antônio José. Metafísica e racionalidade tecnocientífica em Marcuse. Revista PHILIA | Filosofia, Literatura \& Arte, Porto Alegre, volume 2, número 1, p. 58 - 90, junho de 2020. 